\title{
GRAVURA NORTE-AMERICANA NO MUSEU DE ARTE CONTEMPORÂNEA DA USP: UMAANÁLISE DA DOAÇÃO NELSON ROCKEFELLER DE 1950
}

\author{
Carolina Rossetti Toledo'
}

\section{RESUMO}

O artigo analisa a doação de gravuras de Nelson Rockefeller pertencente ao acervo do Museu de Arte Contemporânea da USP. Essa pesquisa interpreta a coleção do MAC USP à luz de um processo internacional de ascensão e valorização da gravura como suporte da linguagem modernista. A doação Rockefeller ao Brasil está associada a um ambiente de inovação gráfica promovida pelo Atelier 17 de Stanley William Hayter em Nova York, e ao crescente interesse curatorial do MoMA e do Brooklyn Museum pela exposição e circulação internacional da gravura nos anos 1940 e 1950.

\section{PALAVRAS-CHAVE}

Atelier 17, Stanley William Hayter, Departamento de Gravuras do MoMA, Doação Nelson Rockefeller, MAC USP.

\begin{abstract}
The article analyzes the Nelson Rockefeller donation of prints that belongs to the Museum of Contemporary Art of USP. This research interprets MAC USP's collection in relation to an international process of ascension and valorization of printmaking as a support of the modernist aesthetics. The Rockefeller donation is directly associated with the environment of graphic innovation championed by Stanley William Hayter's Atelier 17 in New York and the growing curatorial interest of MoMA and the Brooklyn Museum for the international exhibition and circulation of modern printmaking in the 1940s and 1950s
\end{abstract}

\section{KEYWORDS}

Atelier 17, Stanley William Hayter, MoMA Print Department, Nelson Rockefeller, MAC USP.

\footnotetext{
' Mestre em Estética e História da Arte pela Universidade de São Paulo e Masters in Liberal Arts in the Field of Museum Studies, Harvard University Extension School. Realizou estágios em curadoria no Institute of Contemporary Art, Boston, no Departamento de Performance e Arte Contemporânea do Museum of Fine Arts, Boston, no MIT Museum, em Cambridge, e no Museu de Arte de São Paulo Assis Chateaubriand (Masp). Atualmente, ela é Curatorial Fellow das Galerias Bakalar \& Paine do Massachusetts College of Art and Design, Boston.
} 
Poucos meses antes da I Bienal de São Paulo, o antigo Museu de Arte Moderna de São Paulo inaugurou a exposição Gravadores norte-americanos, em 10 de abril de 195I. A mostra foi composta por uma coleção de 27 gravuras doada ao Brasil pelo colecionador e magnata Nelson Rockefeller em 1950. A doação foi realizada por intermédio da equipe curatorial do Museu de Arte Moderna de Nova York (Lytle, 1950) e reunia obras representativas da amplitude técnica e estética da gravura produzida nos Estados Unidos ao final dos anos 1940. Destaque foi dado ao grupo de artistas ligados ao Atelier 17 de Stanley William Hayter, um dos mais importantes centros de experimentação gráfica em Nova York. Entre os artistas incluídos na doação, estão gravuristas associados a Hayter, como Fred Becker, Gabor Peterdi, Seong Moy, Sue Fuller, Minna Citron, Adja Yunkers e Karl Schrag.

A doação de gravuras de 1950 deve ser interpretada como parte de um processo mais amplo de aproximação cultural entre os Estados Unidos e o Brasil, liderado por Nelson Rockefeller e pelo MoMA de Nova York desde meados dos anos 1940. Em 1946, Rockefeller havia realizado uma primeira doação de pinturas e esculturas, com o objetivo de contribuir para a formação do acervo do primeiro museu de arte moderna do Brasil (Toledo, 2015). A doação de 1946 incluiu 14 obras de artistas norte-americanos (Alexander Calder, Jacob Lawrence, Robert Gwathmey, Byron Browne, Morris Graves, Everett Spruce, Arthur Osver) e europeus exilados nos Estados Unidos durante a Segunda Guerra Mundial (Marc Chagall, Fernand Léger,André Masson, Max Ernst, George Grosz e Yves Tanguy). Ambas as doações Rockefeller influenciaram o perfil dos acervos museológicos do Brasil e, em 1963, as duas coleções foram transferidas do MAM-SP para o MAC, fazendo parte hoje do núcleo histórico do museu da USP (Amaral, 1988: 36).

Em 1950, dando continuidade ao diálogo iniciado com o grupo de intelectuais e empresários associados à fundação do MAM-SP e da Bienal de Arte de São Paulo, Nelson Rockefeller realiza uma segunda doação inteiramente de gravuras, no momento em que esse suporte ganhava maior proeminência no cenário artístico norte-americano. $O$ conjunto enviado a São Paulo está diretamente relacionado com a proposta curatorial dos departamentos de gravura do MoMA e do Brooklyn Museum, surgindo do interesse institucional e estratégico de divulgar novas experiências e alcances estéticos da gravura norte-americana.

No catálogo da exposição Gravadores norte-americanos no MAM-SP em I95 I [Fig. I], a curadoria buscou não apenas apresentar as novas experiências da gravura norte-americana, mas também estimular o interesse pela prática no Brasil:

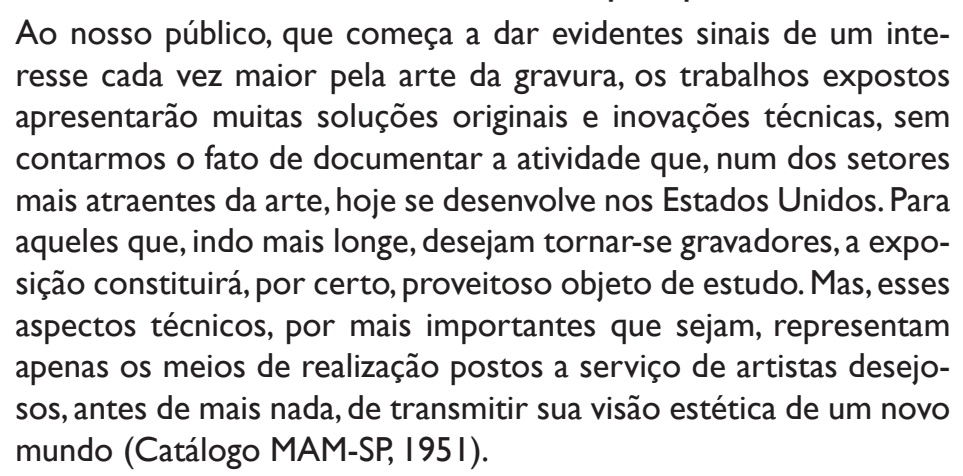

A gravura norte-americana vivenciou um período de ascensão na primeira metade do século $X X$. A valorização deste suporte faz está ligada à 
popularização da gravura nos Estados Unidos por meio do desenvolvimento de associações especializadas, entre as quais a tradicional Society of American Etchers, iniciada em 1913; a Painter-Gravers of America, fundada por John Sloan, George Bellows e John Marin em 1917; Provincetown Printers (19/8), um dos primeiros grupos a encorajar o uso da cor na gravura, e o Silk Screen Group (1940). Esses são exemplos de um universo muito maior de estúdios, entidades de premiação, revistas e clubes de colecionadores de gravuras que floresceram nos Estados Unidos. A transferência do Atelier 17 de Paris para Nova York em 1940 representou um marco no desenvolvimento de novas fronteiras das artes gráficas.A presença cada vez maior de artistas da vanguarda europeia em Nova York, especialmente do gravurista inglês Stanley William Hayter, acelerou a experimentação e a inovação técnica e estética nesse campo.

A segunda doação Rockefeller oferece um panorama significativo do que se chamou de "renascimento da gravura" moderna nos Estados Unidos (LIEBERMAN, I949: I4-I5).A coleção não enfatiza um artista ou estilo, mas uma variedade de experimentações gráficas, desde a litografia, xilogravura, serigrafia, água-tintas e monotipias. $O$ conjunto de 27 gravuras de Nelson Rockefeller é uma importante amostra da produção gráfica mais prestigiada do circuito de arte moderna de Nova York no final dos anos 1940. Assim como a primeira doação Rockefeller de 1946, reaparece a preocupação curatorial de enviar ao Brasil obras de artistas norte-americanos e de europeus imigrados durante a Segunda Guerra Mundial, cujo trabalho havia sido chancelado pelas principais instituições de arte de Nova York. A gravura também aparece nesse período como um suporte recorrente de itinerâncias internacionais promovidas pelo MoMA, em parte devido ao seu baixo custo e facilidade de transporte.

Os artistas contemplados na exposição do antigo MAM-SP de 195I vieram de um ambiente em que a gravura, com a ajuda de museus e grandes colecionadores, vinha ganhando maior repercussão. Em 1947, o Brooklyn Museum passou a organizar exposições inéditas de gravura que foram cruciais para ampliar a visibilidade do suporte. Algumas obras doadas ao Brasil foram prêmios de aquisição das mostras organizadas pelo Brooklyn Museum, evidenciando como a coleção brasileira estava em diálogo com os processos de seleção e divulgação da gravura nos Estados Unidos. O MoMA, por sua vez, também tomou um passo importante em 1949, com a inauguração do Abby Rockefeller Print Room, departamento que sistematizou o conhecimento e debate sobre as novas expressões da gravura. Esse artigo demonstra como os dois museus foram importantes atores na divulgação nacional e internacional dos artistas contemplados na coleção Rockefeller enviada ao Brasil.

Ao traçarmos linhas de contato entre os artistas, os grupos dos quais faziam parte, os estúdios onde trabalhavam, as galerias que comercializavam suas obras, e os curadores que expunham seus trabalhos, vemos surgir um imbricado sistema de arte que ajuda a explicar o florescimento da gravura moderna nos anos 1940. Um fragmento desta história faz parte hoje do acervo do MAC USP. 
Gravura norte-americana no Museu de Arte Contemporânea da USP: uma análise da doação Nelson Rockefeller de 1950

Fig. I. Catálogo da exposição Gravadores norte-americanos do MAM-SP, em I 95 I.

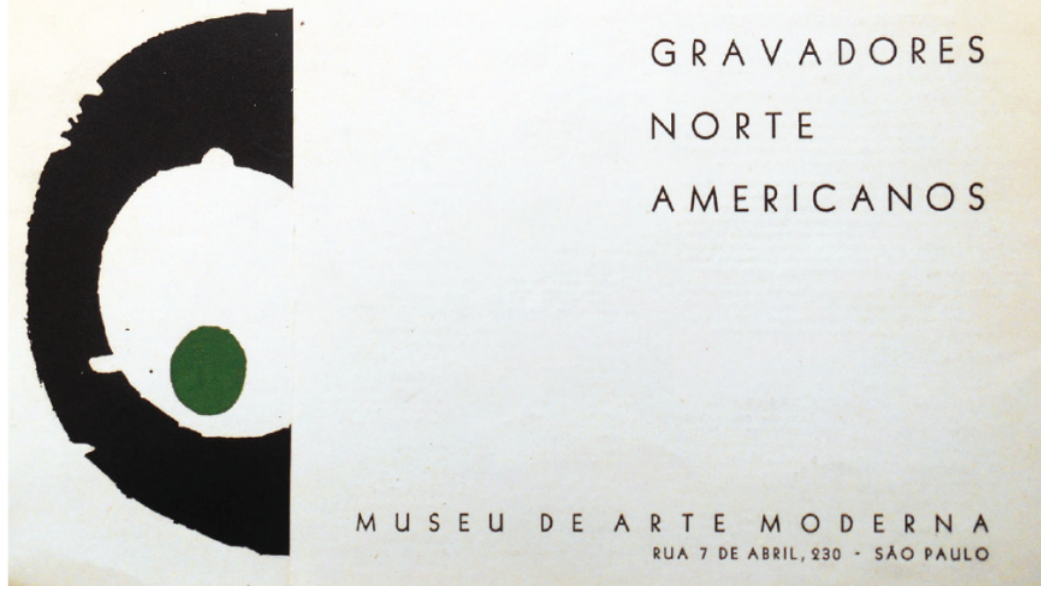

Fonte: Rockefeller Archive Center.

Fig. 2 e 3. Exposição Gravadores Norte-Americanos realizada no MAM-SP em I 95 I.
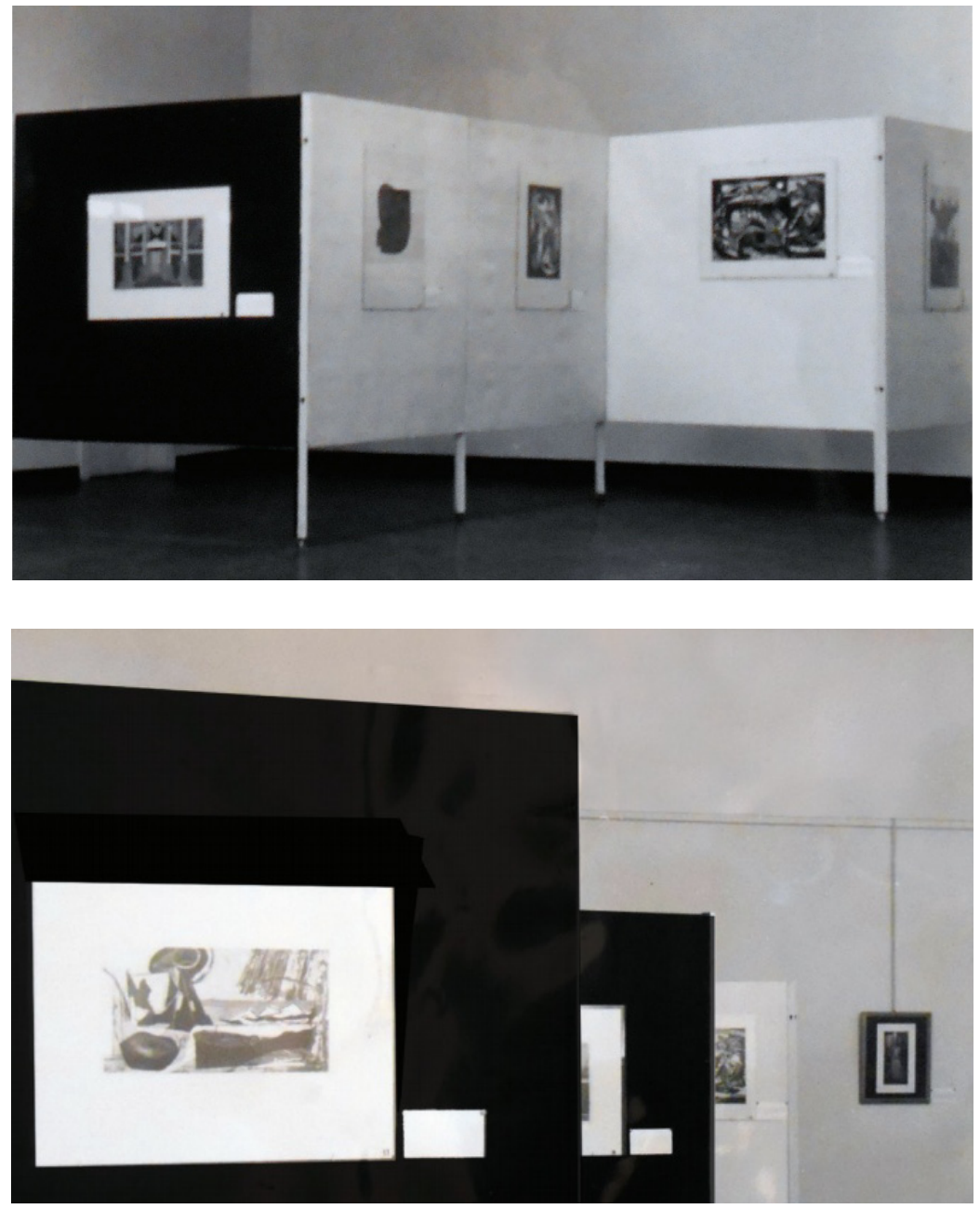

Fonte: Rockefeller Archive Center. 


\title{
O legado dos departamentos de gravura do Brooklyn Museum e do MoMA
}

Abby Aldrich Rockefeller faleceu em abril de 1948. Vítima de um ataque cardíaco fulminante aos 73 anos, a socialite nova-iorquina não sobreviveu para testemunhar a inauguração da sala de gravuras do MoMA que levaria seu nome. Abby Rockefeller mantinha uma impressionante coleção de arte gráfica com obras de mestres europeus e norte-americanos, cuja aquisição começou no final da década de 1920. Em 1940, Abby doou ao MoMA 1.600 gravuras. Os esforços de catalogação, seleção e curadoria desse conjunto custou à equipe do museu o trabalho de quase uma década. Foi apenas um ano depois da morte de Abby Rockefeller que o MoMA organizou a primeira grande exposição com 230 de suas melhores obras em papel.

Entre maio e julho de 1949, a mostra Master Prints apresentou ao público um amplo panorama da gravura moderna dos últimos 65 anos. A exposição teve curadoria de William Lieberman, em colaboração com o primeiro diretor do museu Alfred Barr (Comunicado à imprensa do MoMA, 1949). A mostra procurou situar a coleção inédita de Abby Rockefeller em perspectiva histórica, dando destaque para a vigorosa produção norte-americana, que constituía metade de todo o conjunto. Obras de artistas ligados ao Atelier 17 de Stanley William Hayter foram apresentadas como exemplos do que mais de avançando se fazia em gravura no período. Vários dos artistas associados a Hayter, e incluídos na doação ao Brasil, são mencionados no comunicado à imprensa do MoMA de 1949:

\begin{abstract}
O recente renascimento da gravura Norte-Americana, estimulada em grande medida pelo inglês Stanley William Hayter, está sugerido por obras apresentadas na última galeria. Quando Hayter, em I940, mudou o Atelier 17 de Paris para Nova York, novos experimentos de gravura inspirados em larga medida por seu ensinamento mudaram a direção da gravura norte-americana. Gravuras de seus associados e estudantes incluem trabalhos de Sue Fuller, Raymond Jordan, Mauricio Lasansky, Gabor Peterdi,Andre Racz eYves Tanguy. Aqui também se encontram exemplos de um interesse renovado por xilogravuras de escala e ousadia excepcionais no trabalho de Adja Yunkers e Bernard Reder, europeus agora vivendo nos Estados Unidos, (...) e composições abstratas de Louis Schanker. Técnicas gráficas são de especial interesse nessa última galeria, sugerindo experimentos bem-sucedidos no uso de texturas como tecido e linha, e gravuras sobre celuloide e plástico (Comunicado à imprensa do MoMA, 1949).
\end{abstract}

No dia 12 de maio de 1949, foi oficializado o lançamento do Abby Rockefeller Print Room. Um ano depois, Nelson Rockefeller faria a segunda doação ao antigo MAM-SP. A seleção das 27 gravuras enviadas ao Brasil precisa ser compreendida a partir do trabalho curatorial desempenhado por Lieberman à frente dessa seção de gravuras do MoMA e do colecionismo de Abby Rockefeller.

William Lieberman se tornou um dos mais importantes e influentes especialistas em gravura dos Estados Unidos. À frente do departamento do MoMA para gravuras e desenhos, ele foi responsável pela aquisição de obras importantes para o museu. Foi sob a gestão Lieberman que a coleção de Abby Rockefeller ganhou corpo e contexto. Em uma entrevista, Lieberman relembra como o acervo de gravuras e desenhos não era uma das prioridades da direção artística durante as primeiras décadas de funcionamento do museu. Segundo ele, 
foi apenas por causa da insistência de Abby que o Print Room se concretizou. "Tornou-se aparente, quase imediatamente após minha chegada (ao museu), que algo precisava ser feito com a coleção de gravuras, então comecei a colocar aquilo em ordem (...). Miss Abby estava martelando para que isso fosse realizado. Certamente não era uma das prioridades de Alfred (Barr). Com base nas aquisições dela, eu transformei aquela coleção na melhor coleção de gravuras modernas em existência" (LIEBERMAN, 1990: 43).

O conjunto de Abby Rockefeller, que posteriormente se tornaria 0 núcleo do acervo de artes gráficas do mais importante museu de arte moderna do mundo, nasce de um projeto pessoal de aquisição, só possível devido a sua curiosidade estética implacável pela nova arte e aos seus recursos financeiros ilimitados. Suas aquisições frequentemente privilegiavam gravuras nacionais a pinturas de mestres europeus. Dessa maneira, Abby foi capaz de financiar uma legião de artistas dos Estados Unidos e manter um punhado de galerias locais em contínuo crescimento.

Ela sentia que essa abordagem lhe rendia os melhores trabalhos de artistas desconhecidos e trabalhos de segunda categoria de artistas com reputações mais estabelecidas. O sistema resultou em uma coleção altamente particular, cuja diversidade é um testemunho de seu gosto excelente. Eventualmente, (a coleção) iria formar o núcleo do Abby Aldrich Rockefeller Print Room, do MoMA (LOEBL, 2000: 236I).

A ideia de batizar um departamento com o nome de Mrs. Rockefeller foi sugestão de Alfred Barr. Em carta a Nelson Rockefeller, Barr explicou que, devido à grande modéstia de Abby e a sua vontade em vida de não ter o nome associado a obras doadas ao MoMA, a melhor forma de homenagear sua imensa contribuição seria atrelar o nome de Abby a um de seus maiores interesses: a gravura moderna. No catálogo do lançamento do Abby Aldrich Rockefeller Print Room, Barr escreveu:

Mrs. Rockefeller, com gentil insistência, argumentou pela inclusão da sala de gravura, lembrando seus colegas que gravuras, porque têm preços baixos o suficiente para estarem disponíveis em uma escala democrática, deveriam ter um lugar especialmente importante em um museu preocupado em encorajar o amplo colecionismo de obras originais de artistas vivos (BARR, 1949:7).

Abby Rockefeller teve papel central no incentivo e financiamento das novas expressões estéticas da arte do início do século $X X$ e na consolidação de um poderoso modelo institucional para a arte moderna, com a criação do MoMA. Sua paixão e contínuo investimento em obras sobre papel, que eram mais acessíveis do que pinturas e esculturas, estão na raiz da fundação de um departamento específico para a curadoria de gravuras. $O$ contexto da doação a São Paulo está atrelado, portanto, a esse crescente prestígio da gravura e a um novo direcionamento institucional do MoMA em 1949.

A partir de 1940, novas técnicas e abordagens da gravura estavam sendo desenvolvidos por coletivos de artistas trabalhando nos Estados Unidos: Stanley William Hayter havia desenvolvido uma técnica de gravura em buril que permitia aplicar múltiplas cores a partir de uma mesma prancha; Adja Yunkers (Fig. 6), introduziu novos suportes com o uso de celuloide no lugar da prancha de metal ou madeira; Sue Fuller (Fig. I0) experimentou com a aplicação de tecidos e rendas na composição de suas gravuras; e Seong Moy (Fig. 9) participou do movimento de retomada do método tradicional da xilogravura por artistas abstratos. $A$ 
coleção Rockefeller também incluiu artistas não vinculados a Hayter, mas que eram identificados com a excelência em técnicas gráficas, como Armin Landeck na litografia figurativista, e Edward Landon na serigrafia, assim como artistas ligados ao ambiente da gravura em Chicago, como Max Kahn e Eleanor Cohen.

Apesar da inquestionável proeminência do conjunto de obras de papel do Abby Rockefeller Print Room e da importância da exposição inaugural Master Prints, não longe do MoMA estava se formando outra coleção de igual estatura: a seção de gravuras do Brooklyn Museum. Constituída em 1937 a partir da divisão das obras sobre papel do acervo da biblioteca do museu, a coleção do Brooklyn se transformou em um rico repositório das expressões mais inovadoras da gravura moderna.A curadora Una Johnson teve um papel decisivo no patrocínio e estímulo de gravuristas atuando em Nova York nos anos 1940, tornando-se uma das figuras mais influentes da arte gráfica nos Estados Unidos. Johnson assumiu a direção do setor de gravuras e desenhos do Brooklyn Museum em 1941. Em 1947, ela fundou as exposições anuais de gravura, que contavam com mais de 200 obras por edição e consagrariam o museu como um centro de desenvolvimento, divulgação e discussão de novas experiências gráficas.

As exposições do Brooklyn Museum apresentam semelhanças curatoriais com a doação Rockefeller ao Brasil [Tab. I]. De 1947 a 1950, 8 das 27 obras doadas ao Brasil estiveram presente nos National Print Annuals do Brooklyn Museum, sendo quatro obras vencedoras do prêmio de aquisição: Cat walk [Passeio do gato] (1949) de Max Kahn, Rain and sea [Chuva e o mar] (1946) de Karl Schrag, Heavy bird [Pássaro pesado] (1950) de Marjean Kettunen, e Self-analysis [Autoanálise] (1947) de James Louis Steg. Além dessas, outras obras presentes no MAC USP integraram as mostras anuais, como Dead bird [Pássaro morto] de Adja Yunkers, Alleyway [Passagem no beco] (1948) de Armin Landeck, Eternal wanderer [Eterno errante] de Henry Mark e The sea [O mar] (1950) de Boris Margo. O Brooklyn adquiriu ainda a gravura Carnival [Carnaval] de Louis Schanker e Hen [Galinha] de Sue Fuller, obras que também estiveram presentes em Master Prints, do MoMA, e cujos exemplares fazem parte do acervo do MAC USP.

Há, portanto, pontos de contato importantes entre $\circ$ trabalho desenvolvido nos departamentos de gravura do MoMA e do Brooklyn. O processo de seleção que norteou a curadoria dessas instituições está refletido em larga medida no conjunto de obras sobre papel doado ao Brasil. A coleção do MAC USP se mostra, portanto, bastante atualizada, composta de artistas prestigiados, aceitos pela crítica modernista, cobiçados pelo mercado de gravuras, vendidos nas principais galerias de arte moderna de Nova York, e cujas obras, no final dos anos 1940, já se faziam presentes nos acervos dos principais museus de arte moderna dos Estados Unidos.

\section{O papel da gravura na democratização da arte moderna}

A ascensão da gravura moderna em meados dos anos 1940 é um fenômeno artístico melhor compreendido se levado em conta dois outros aspectos, um de âmbito econômico e outro político. Depois da Segunda Guerra Mundial, a economia norte-americana estava a todo vapor e passava por um período de crescimento. Em 1945, a estrutura política do mundo se alterava. Novas alianças eram formadas e, ao longo do século $X X$, a presença diplomática, a influência cultural e o poderio econômico se tornariam instrumentos importantes da Guerra Fria. É neste cenário em que gravura moderna norte-americana se prolifera. É sob essa ótica que a doação Rockefeller ao antigo MAM-SP deve ser interpretada. 
Gravura norte-americana no Museu de Arte Contemporânea da USP: uma análise da doação Nelson Rockefeller de 1950

Tab I. Presença das obras da doação Rockefeller em exposições do MoMA e Brooklyn Museum.

\begin{tabular}{|c|c|c|}
\hline Artista & Obra & Exposição \\
\hline Minna Citron & Marine & Master Prints, MoMA, 1949. \\
\hline Sue Fuller & Hen (1945) & Master Prints, MoMA, 1949. \\
\hline Stanley W. Hayter & Tarantelle (1943) & Master Prints, MoMA, 1949. \\
\hline Raymond Jordan & Synthesis (1948) & Master Prints, MoMA, 1949. \\
\hline Kenneth Kilstrom & $\begin{array}{c}\text { Attack on Mar- } \\
\text { shall Gilbert } \\
(1948)\end{array}$ & Master Prints, MoMA, 1949. \\
\hline Armin Landeck & Alleyway (1948) & $\begin{array}{c}\text { Master Prints, MoMA, } 1949 . \\
\text { National Print Annual, Brooklyn Museum, } 1949\end{array}$ \\
\hline Boris Margo & The Sea (1949) & Master Prints, MoMA, 1949. \\
\hline Alton Pickens & Pastorale (1947) & Master Prints, MoMA, 1949. \\
\hline Adja Yunkers & Dead bird (1947) & $\begin{array}{l}\text { Master Prints, MoMA, } 1949 . \\
\text { Recent American Woodcuts, MoMA, } 1952\end{array}$ \\
\hline Max Kahn & Cat walk (1949)* & National Print Annual, Brooklyn Museum, 1949 \\
\hline Karl Schrag & $\begin{array}{l}\text { Rain and sea } \\
\qquad(1946)^{*}\end{array}$ & National Print Annual, Brooklyn Museum, 1947 \\
\hline Marjean Kettunen & $\begin{array}{l}\text { Heavy bird } \\
(1950)^{*}\end{array}$ & National Print Annual, Brooklyn Museum, 1950 \\
\hline James Louis Steg & $\begin{array}{l}\text { Self-analysis } \\
(1947)^{*}\end{array}$ & National Print Annual, Brooklyn Museum, 1947 \\
\hline Henry Mark & $\begin{array}{l}\text { Eternal wanderer } \\
\qquad(1947)\end{array}$ & National Print Annual, Brooklyn Museum, 1947 \\
\hline Louise Krueger & $\begin{array}{l}\text { The Boaters } \\
\text { (1948) }\end{array}$ & Recent American Woodcuts, MoMA, 1952 \\
\hline Anne Ryan & $\begin{array}{l}\text { The Captive } \\
\qquad(1946)\end{array}$ & Recent American Woodcuts, MoMA, 1952 \\
\hline Louis Schanker & Carnival (1945) & Recent American Woodcuts, MoMA, 1952 \\
\hline Frank Wallace & Pompei I (1949) & Recent American Woodcuts, MoMA, 1952 \\
\hline
\end{tabular}

* Prêmios de aquisição das exposições anuais do Brooklyn Museum. 
Diante de uma Europa estraçalhada, o eixo econômico do mundo se movia para os Estados Unidos. A fuga de intelectuais e artistas europeus fazia com que, gradativamente, Paris perdesse sua proeminência no cenário cultural. A classe média, fortalecida por programas de fomento do governo Roosevelt, chegava à década de 1940 com uma nova musculatura econômica. Insuflados por um período de recuperação, os norte-americanos se transformaram nos principais compradores de objetos de arte do Ocidente.

Levantamento de Serge Guilbaut demostra o crescimento exponencial do mercado de arte em Nova York:

\begin{abstract}
O "boom da arte" seguiu o "boom da economia". De repente o país parecia ter desenvolvido um apetite insaciável pelas artes. (...) O número de galerias em Nova York cresceu de 40 no começo da guerra para $150 \mathrm{em} 1946$ (...) A arte se tornava uma commodity e a galeria um supermercado (GUILBAUT, 1983: 91-92).
\end{abstract}

Nesse hipermercado da arte, a gravura, a fotografia e as reproduções ganharam cada vez mais espaço. $O$ mercado de arte estava aquecido e as obras em papel, por terem um preço acessível, eram um produto cultural atraente para um público crescente. $O$ perfil do colecionador se ampliava. Para atender a nova demanda, galerias se adaptaram, criando diferentes maneiras de expor e comercializar. Publicações especializadas com o objetivo de informar o novo colecionador se tornavam mais numerosas. Catálogos enviados pelo correio, anúncios em jornais e vendas por telefone passaram a ser métodos incorporados por algumas galerias voltadas para um público ampliado de apreciadores.A gravura encontra o seu lugar neste cenário por suas qualidades materiais.A arte gráfica é um suporte de baixo custo, de rápida produção, voltada para a reprodutibilidade em série, assim ampliando a capacidade de divulgação da arte moderna.

Em 1945, era possível comprar uma gravura premiada de Stanley William Hayter, como Tarantelle [Tarantela], por US $\$ 45,{ }^{2}$ ou uma xilogravura de Anne Ryan, The captive [O cativo] por US $\$ 40 .{ }^{3}$ Obras de menor calibre ou de artistas menos conhecidos podiam ser adquiridas por até um terço do preço. A obra Composition in oval [Composição em oval], de Jim Forsberg, que também faz parte da doação Rockefeller, foi adquirida por US\$ 15 da galeria Jacques Seligman \& Co.A acessibilidade da arte moderna talvez nunca tenha sido tão ampla quanto no ambiente criado pela profusão e concorrência de galerias nova-iorquinas nos anos de recuperação econômica do pós-guerra. ${ }^{4} \mathrm{~A}$ lista de aquisição enviada para o Brasil aponta oito galerias que venderam as 27 obras por US\$ I, I54 no total (LYTLE, 1950).

A principal fonte foi a Weyhe Gallery, fundada em 1914 pelo imigrante alemão Erhard Weyhe, por intermédio do qual foram adquiridas as xilogravuras de Louise Krueger The boaters [Os barqueiros] (1949), Bernard Reder Fighting cocks [Galos de briga] ( I949), Frank Wallace Pompei I [Pompéia I] ( 1949) e Misch Kohn Tiger [Tigre] (1950); a água-tinta e verniz mole de Minna Citron Marine [Marinha] (1948); a litografia de Eleonor Coen Baby in the high chair [Bebê na

\footnotetext{
${ }^{2}$ Catálogo da exposição American Printmakers, Galeria Buchholz, 1945. Archives of American Art, Smithsonian Institution, Washington D.C.

${ }^{3}$ Documento com lista de preços de obras de Anne Ryan da Galeria Betty Parsons (sem data), Archives of American Art.Ainda que esta galeria tenha vendido um exemplar da gravura Captive de Anne Ryan, a obra que chega ao Brasil foi intermediada diretamente pela artista no mesmo valor de US\$40, segundo indica o documento encontrado nos arquivos do MoMA. LYTLE, [Dorohy L.] (carta) 28 de junho de 1950, Nova York [para] BOYER, Nova York. 2 f.

${ }^{4}$ O salário mínimo de um trabalhador americano em 24 de outubro de 1945 era no valor de US\$ 64, valores da época, para uma jornada mensal de trabalho de 160 horas, segundo registro do Departamento de Trabalho dos Estados Unidos. Disponível em: http://www.dol.gov/whd/minwage/chart.htm
} 
cadeira de pés altos] (1950); e as duas gravuras premiadas nas exposições anuais do Brookyn Museum Self-analysis [Autoanálise] (1947) de James Steg e Heavy bird [Pássaro pesado] (1950) de Marjean Kettunen [Tab.2].

Uma galeria que tinha como objetivo específico de expandir a comercialização de obras de arte para a classe média era a Associated American Artists, de Reeves Lewenthal, fundada em 1934."Ninguém é pobre demais para comprar uma obra-prima", descreveu um jornalista ao escrever uma reportagem sobre AAA (DOSS, I99I: I5I). Lewenthal se associou ao Society of American Etchers, grupo ligado a Thomas Benton na Art Student League, garantindo assim uma produção contínua de gravuras que pudessem ser vendidas a US $\$ 5$, com um adicional de US\$2 pela moldura. "O sistema de galeria está arruinado", diria Lewenthal. "A classe do colecionador rico está morrendo (...) Arte norteamericana deve ser tratada como qualquer outro negócio" (apud DOSS, 1991:145). Até 1937, estima-se que a AAA já tinha vendido 70 mil gravuras. A Associated American Artists trabalhou com Adja Yunkers e Gabor Peterdi, cujas obras Dead bird [Pássaro morto] (1947) e Sign of the lobster [Sinal da lagosta] (1947-48) integram a doação Rockefeller de 1950 e as exposições do MoMA. Ao longo dos anos 1940, a AAA perdeu, contudo, sua reputação entre a classe artística, principalmente por começar a fazer artigos de decoração de interiores, como tapetes, cinzeiros, abajures e padrões de tecidos. "Se tornou quase degradante comprar da AAA", declarou o galerista Sylvian Cole (apud DOSS, 1991:166). Para a historiadora da arte Erica Doss, a galeria de Lewenthal serviu como um atenuador ao estresse econômico de artistas trabalhando durante o período de Depressão, mas seu prestígio e posição durante o reaquecimento do mercado da arte foi continuamente diminuído ao longo dos anos 1940.

Tab.2. Galerias de Nova York que intermediaram a venda das obras da doação Rockefeller ao MAC USP.

\begin{tabular}{|l|l|c|}
\hline Doação I950 & Artistas & Valor (US\$ em 1950) \\
\hline George Binet Galleries & Max Kahn & 45 \\
\hline Buchholz Gallery & Stantley W. Hayter, Alton Pickens & 80 \\
\hline Kennedy \& Co & Armin Landeck & 24 \\
\hline Kraushaar Galleries & Karl Schrag & 25 \\
\hline Bertha Schaefer Gallery & Worden Day, Sue Fuller & 75 \\
\hline Jacques Seligman \& Co & $\begin{array}{l}\text { jim Forsberg, Boris Margo, Seong } \\
\text { Moy, Louis Schanker }\end{array}$ & 135 \\
\hline Serigraph Galleries & Edward Landon, Henry Mark & 35 \\
\hline Weyhe Gallery & $\begin{array}{l}\text { Minna Citron, Eleanor Coen, } \\
\text { Marjean Kettunen, Misch Kohn, } \\
\text { Louise Krueger, Bernard Reder, } \\
\text { Louis Steg, Frank Wallace }\end{array}$ & 385 \\
\hline Venda pelo próprio artista & $\begin{array}{l}\text { Raymon Jordan, Kenneth Kils- } \\
\text { trom, Guy Mayer (Fred Becker), } \\
\text { Gabor Peterdi,Anne Ryan, Adja } \\
\text { Yunkers }\end{array}$ & 350 \\
\hline Total & \\
\hline
\end{tabular}


Os museus também desempenharam um papel importante na tentativa de aumentar a aquisição de arte pela classe média. $O$ comunicado à imprensa de Master Prints citava:"o valor das gravuras, que variam de $\$ 25$ a quase $\$ 2$ mil, indicam, por um lado, a acessibilidade das gravuras originais até mesmo para o colecionador mais modesto e, ao mesmo tempo, a alta estima que o suporte pode atingir" (MoMA, 1949). O MoMA, voltado desde sua inauguração ao ensino e formação de um público para a arte, promoveu ao menos 10 exposições de gravuras e objetos de design com valores iniciais de US\$ 5 a US\$10 na década de $1940 .{ }^{5}$ As primeiras exposições deste tipo estavam ligadas à produção saída das oficinas do Federal Art Project.

Criado em 1935 pelo governo Roosevelt para ser o New Deal da arte, o FAP era um braço do Work Projects Administration, o principal órgão federal responsável pelo estímulo à produção cultural nos Estados Unidos de 1935 a 1943. Neste período, 32 mil artistas foram empregados pelo Works Project Administration, enquanto II.285 gravuras originais e 250 mil reproduções foram realizadas (DOSS, 1991, p. 145). O custo estimado do programa foi de US\$ 35 milhões. A Seção de Artes Gráficas do FAP foi criada em 1936 e o primeiro estúdio de gravura foi fundado em Nova York. Artistas tinham que cumprir cotas de produção e recebiam um salário de $\$ 23.86$ por semana. As gravuras produzidas tinham tiragens de 25 a 30 exemplares, sendo que três ficavam para o artista. As obras eram enviadas para decorar prédios públicos, hospitais e escolas.

Em novembro de 1940, o MoMA promoveu duas pequenas exposições simultâneas ao ArtWeek, evento anual doWPA para divulgar a produção artística do programa. O objetivo era estimular a compra de obras de artistas nacionais nas semanas próximas ao feriado natalino. Color prints under ten dollars [Gravuras coloridas a menos de dez dólares] disponibilizou 79 serigrafias de artistas americanos, muitos dos quais vinculados ao programa do WPA. O slogan "buy american", reforçado no comunicado à imprensa, mostra como a preocupação protecionista naquele momento se estendia não só à indústria, mas também à produção artística. Alfred Barr e Nelson Rockefeller apoiaram publicamente o programa governamental de fomento às artes. Alfred Barr declarou que estava "muito encorajado pela qualidade (das obras) do WPA e acredito que seria um sério choque para a cultura norte-americana caso ele seja descontinuado" (apud HARRIS, 1995: I34). Barr tinha sido eleito presidente do Conselho de Nova York para o ArtWeek em 1940. Para ele, o objetivo da semana de arte era "chamar atenção das pessoas em todos os lugares para os trabalhos de artistas nacionais de forma a encorajar a aquisição de arte norte-americana em todos os lares" (apud HARRIS, I995: I 52).

Em março de 1942, o Works Projects Administration Art Program foi descontinuado. Parte da administração do programa foi transformada na Seção Gráfica do War Services Program. As encomendas para os artistas passaram a ser de natureza militar: design de uniformes de camuflagem, produção de mapas, pôsteres com mensagens de guerra e ilustrações para manuais. $O$ Federal Art Project foi um importante viabilizador do fazer artístico durante a Depressão. Artistas saídos do programa ganhariam espaço no mercado privado e alguns passariam a ser estrelas do circuito crescente de galerias em Nova York nos anos 1940 e 1950. Um grupo grande de artistas outrora vinculados ao programa federal entraria para o acervo do MoMA e para as coleções privadas da família

${ }^{5}$ Lista de exposições realizadas pelo MoMA (1940-1949). Arquivo do MoMA. 
Rockefeller.

Outro vetor importante para a popularização da gravura norte-americana em escala internacional foi o trabalho desenvolvido pelo Departamento de Circulação de Exposições do MoMA. Desde seu início, a missão do museu era formar público e ser a plataforma de divulgação de conhecimento sobre a arte moderna.A vocação didática do MoMA se fez sentir já nos seus primeiros anos de funcionamento, com programas voltados a escolas e exposições itinerantes. Em 1952, o museu recebeu financiamento da fundação dos irmãos Rockefeller para implementar um robusto programa internacional de divulgação artística, sob coordenação de Elodie Courtier e depois de Porter A. McGray. Se em 1938 a primeira exposição internacional do museu tinha sido pensada apenas para circular em Paris, ao longo da década seguinte a presença institucional do MoMA ganharia maior fôlego e seria sentida na América Latina, Ásia e Austrália. Ao todo, o museu montou exposições de seu acervo em 37 nações (MoMA Bulletin, 1954). Uma dessas exposições incluiu, por exemplo, a delegação norteamericana na II Bienal de São Paulo.

Neste contexto, a gravura foi ferramenta importante de divulgação da arte moderna. Com financiamentos módicos, era possível montar sucessivas exposições itinerantes de gravuristas modernos em cidades da América Latina. Em 1944, o departamento realizou a exposição Silk screen prints e, no ano seguinte, New directions in gravure, sobre o trabalho desenvolvido pelo Atelier 17. Apenas no ano de 1954, foram organizadas cinco exposições de gravura moderna: The American woodcut today, Contemporary printmaking in U.S.A, Thirty American printmakers, Twenty five American prints e Young American printmakers. Essas mostras eram facilitadoras de uma aproximação política e cultural com os países pelos quais passavam.

O trabalho do departamento internacional do MoMA é importante para se entender a segunda doação Rockefeller ao Brasil, pois grande parte da coleção surge justamente de uma dessas exposições itinerantes. Em agosto de 1944, o MoMA coroou a produção do grupo com uma exposição Hayter and Studio 17: new directions in gravure [Hayter e Atelier 17: novas direções na gravura]. O curador da mostra, James Johnson Sweeney, descreveu o trabalho desse núcleo como "uma das mais vitais pesquisas em arte gráfica do século XX". Para ele, Hayter e seus associados "recuperaram a dignidade da gravura em buril como um meio de expressão original" (Sweeney, 1944). Havia um interesse por parte dos apoiadores do atelier e da curadoria do MoMA de equiparar a gravura a outros meios de desenvolvimento artístico da vanguarda, como a pintura e a escultura, e reafirmá-la enquanto suporte necessário de ser tomado em consideração pelo mercado e crítica. O núcleo artístico do Atelier 17 tinha posição de destaque na exposição do MoMA e, não por acaso, esse grupo compõe 17 das 27 obras Rockefeller doadas ao Brasil.

Sobre o atelier, o curador William Lieberman escreveu:

Uma repentina renascença começou em 1940 quando o inglês Stanley William Hayter transferiu seu estúdio, Atelier 17, de Paris para Nova York. Novos experimentos inspirados pelo ensinamento de Hayter, sua insistência no buril e engenhosa aplicação de texturas na gravura com verniz mole, em larga medida mudou a direção da produção da gravura norte-americana. (LIEBERMAN, I949: |4-I5).

Hayter gradativamente assumiria um papel de artista-curador, auxiliando na organização de exposições de gravura no MoMA (LIEBERMAN, 1990). Por causa da proximidade curatorial com essas exposições itinerantes, a doação 
Rockefeller precisa ser entendida como parte de um projeto maior de divulgação cultural e promoção da arte moderna norte-americana nos países de interesse estratégico para os EUA durante a Guerra Fria - um projeto que estava em diálogo com as tendências do mercado artístico da Nova York, que fazia parte do colecionismo desempenhado por Abby Rockefeller e estava em sintonia com o trabalho da primeira geração de curadores do MoMA.

\title{
Atelier 17: um centro de inovação
}

Um dia típico no Atelier 17 começava com o fluxo errático de entrada e saída de seus frequentadores e o barulho do buril contra madeira e chapas de metal. Artistas iam e vinham livremente. Sentavam-se nas ilhas de trabalhos, dedicando-se por longas horas a suas composições. O Atelier 17 não era uma escola. Não havia aulas, turmas ou horários. De acordo com a visão de Hayter, aquele deveria ser um espaço de convívio social e dedicação total à arte da gravura. Todos os materiais necessários para a produção das obras eram fornecidos pelo próprio estúdio.Todas as mesas e prensas eram comunitárias. $O$ ambiente não era muito sofisticado, pois Hayter preferia investir os rendimentos obtidos na compra de materiais e na subsistência de estudantes promissores, e não na aquisição de novos equipamentos. Enquanto os artistas trabalhavam, Hayter sobrevoava os postos de trabalho com olhar certeiro de um observador experiente, tecendo comentários e críticas individualizadas. Ele atuava mais como um orientador do que propriamente um professor. Raramente trabalhava em suas próprias gravuras durante o tempo que passava no atelier. Naquele espaço, dedicava-se ao desenvolvimento dos outros e a discussões conceituais sobre propostas estéticas e filosóficas das vanguardas. O Atelier 17 era um espaço para o fazer técnico, mas também um centro para o debate artístico.

\section{Em About prints, Stanley William Hayter descreve:}

\begin{abstract}
Algumas grandes mesas dão espaço e luz suficiente para trabalhar nas placas (...) um canto contém os ácidos e uma pia; no outro, papel e gravuras secando são empilhados. Há três prensas e todo o equipamento, apesar de muito caro, é rudimentar em comparação com outros estabelecimentos educacionais privados fundados por ex-membros do grupo. Embora tenha sido confundido como tal, o Atelier 17 não é uma escola, exceto na medida em que todo o grupo e aqueles que trabalharam nele, agora espalhados em uma dúzia de países, constituem uma 'Escola' no sentido histórico. A qualquer momento, artistas maduros de reputação internacional podem estar trabalhando ao lado de artistas menos conhecidos de gerações diferentes e até mesmo alguns poucos estudantes de arte (HAYTER, 1960: 62).
\end{abstract}

Nascido em 1901, Hayter formou-se em química e geologia no Kings College de Londres. Depois da graduação, trabalhou três anos para a companhia Anglo-Iranian Oil, ocasião em que foi alocado para a cidade de Abadan. Mesmo neste emprego, investia grande parte de seu tempo e energia no desenvolvimento de suas habilidades artísticas, que veio a aprofundar quando retornou à Europa. Em 1926, mudou-se para Paris e passou a frequentar os círculos da vanguarda. Entre os seus principais interlocutores naquele período, constam Alexander Calder,Anthony Gross, Joan Miró e Alberto Giacometti.

Em Paris, o atelier começou com um grupo de quatro artistas que trabalhavam lado a lado no apartamento de Hayter na Rua Campagne-Première, n. I7. No estúdio, artistas iniciantes conviviam com Max Ernst, Joan Miró,Alberto 
Giacometti, Jean Hélion, Yves Tanguy, Pablo Picasso e Vassily Kandinsky (LÉVY, 2003: I54). Quando Hayter migrou para os Estados Unidos, grandes nomes da vanguarda norte-americana também frequentaram o seu estúdio; Frank Kline, Robert Motherwell,Willem de Kooning e Jackson Pollock.

Hayter se mudou para os Estados Unidos em 1937. Com ele, vieram suas ideias sobre o papel do subconsciente e da abstração na arte. Ligado ao movimento surrealista francês, a chegada de Hayter a Nova York ventilou a cena da arte gráfica norte-americana com propostas estéticas inovadoras. Para a historiadora da arte Joann Moser, artistas no Atelier 17 estavam expostos a muito mais do que informação técnica. "As ideias de Hayter sobre arte estavam de acordo com o pensamento mais avançado da arte moderna e ajudou a gerar nova vitalidade na produção da gravura moderna norte-americana que, com raras exceções, era relativamente conservadora" (MOSER, 1978: 2). Em 1940, Hayter transferiu o atelier para uma sala do New School for Social Research em Nova York, uma escola de atmosfera liberal e progressista. A partir de 1945, procurando maior independência institucional, ele mudaria o estúdio para um espaço maior em Greenwich Village. Aos poucos, o atelier se popularizou e o número de frequentadores escalonou.

O artista cantonês radicado em Minnesota, Seong Moy, descreveu a experiência do atelier:

Era uma situação muito diferente. Acho que foi, provavelmente, a situação mais ideal para qualquer artista que tem algum conhecimento prévio. Não é o lugar onde se ensina algo muito rudimentar. Você tem que ter alguma experiência quando você vai lá, porque o que é feito não é ensino, é uma troca de pontos de vista, intercâmbio de ideias, a procura por alguma novidade em inovações técnicas (MOY, 197I).

Para Karl Schrag, outro artista do Atelier 17, e quem Hayter escolheria para continuar a administrar o estúdio depois de seu retorno para Paris, relatou:

O Atelier era um ponto de encontro onde se discutiam problemas muito além da gravura. Não era nada parecido com uma escola. (Ali era discutido) todo o contexto do que a arte gráfica poderia ser, e também os elementos que compunham a gravura, como a linha, os valores e a cor. Toda complexidade do problema tornava-se visível e você podia fazer sua própria escolha. Para mim, foi um lugar útil. Primeiro, há algo inspirador no ar quando você está trabalhando em conjunto com pessoas extremamente criativas. Mas, além disso, havia a enorme ampliação do alcance das possibilidades gráficas, que nos dava não tanto a possibilidade de utilizar todos esses suportes, mas entender quais técnicas realmente atendiam sua própria necessidade (SCHRAG, 1970).

Ao ingressar no atelier pela primeira vez, o artista novato seria convidado a participar de uma experiência. Reconhecido pela sua habilidade no processo do intaglio, Hayter fornecia uma placa de metal a ser trabalhada livre e intuitivamente pelo artista. A recomendação era não ter medo de estragar o suporte. Quanto mais automático o traço, melhor. $O$ objetivo desta primeira aproximação com o trabalho do estúdio visava encorajar novatos a explorarem a natureza do material.

Uma placa de zinco era preparada com uma camada suave na qual o recém-chegado era convidado a fazer um 'desenho automático' que utilizasse todo o espaço disponível, mas que não sugerisse contornos, objetos, texturas, ou luz e sombra. Esse procedimento introdu- 


\begin{abstract}
zia o artista na prática de trabalhar diretamente com a placa ao invés de copiar um desenho preparatório. Ele também eliminava a noção de que um desenho deveria descrever algo ou sugerir uma imagem reconhecível. Porém, mais importante, Hayter tinha a intenção de que essa ação fosse tão diferente dos procedimentos tradicionais do desenho que provocaria uma situação nada familiar em que uma descoberta era mais provável de acontecer (MOSER, 1978: 3).
\end{abstract}

A porta de entrada para o grupo do Atelier 17 exigia, portanto, um processo de estranhamento. $O$ artista deveria se despir de seus maneirismos e sair da zona de conforto. Hayter promovia o abstracionismo por meio do método de desenho automático empregado por surrealistas ligados a André Breton nos anos 1920.Um exemplo dessa abordagem é a gravura Tarantela [Fig.4],apresentada pela primeira vez em na exposição New ways of gravure, do MoMA, em 1944. No Atelier 17, esse método procurava criar um constrangimento inicial para o artista e chamar atenção para as qualidades intrínsecas do suporte. Segundo a historiadora da arte Joann Moser, Hayter encorajava esse procedimento, pois ele permitiria perceber que a gravura não era apenas uma extensão do desenho ou da pintura, mas era dotada de características e possibilidades singulares. "Assim como havia inspirado os surrealistas, essa investida ao desconhecido, ao não premeditado, ao incerto, excitava as imaginações de muitos artistas que buscavam uma nova fonte de inspiração" (MOSER, I 978: 3). O passo seguinte era trabalhar a placa de zinco cingida e mergulhá-la em ácido:

Em cada etapa sucessiva no desenvolvimento da placa, uma prova era realizada para revelar imediatamente para o artista qual o resultado de sua ação anterior e registrar a transformação gradual do desenho em imagem. Ainda que a placa fosse trabalhada repetidas vezes ao ponto que precisava ser abandonada, a experiência familiarizava o artista com as técnicas básicas do intaglio e servia de ponto de partida para o próximo esforço (HAYTER, 1978: 4).

O estúdio de Hayter era, acima de tudo, um laboratório experimental. Acidentes de percurso eram incentivados. A formação em química dava a Hayter conforto para testar diferentes solventes, ácidos e metais. Os efeitos inesperados desses desvios eram explorados e inseridos nas composições. Os artistas recebiam instruções básicas sobre as técnicas tradicionais da gravura e todo novo passo era uma descoberta. $O$ objetivo era que, com apenas a mínima orientação, eles pudessem descobrir todos os processos por meio da manipulação prática. Um dos pontos de investigação central era o desenvolvimento da gravura de múltiplas cores realizada em uma mesma placa de metal.

O método tradicional de inserir cor às gravuras consistia no uso de várias pranchas tingidas com cores diferentes. Hayter orquestrou uma maneira que lhe permitia a exposição simultânea das cores sobre a mesma placa, obtendo uma delicada transparência cromática e maior economia de materiais. $O$ método de Hayter envolvia cobrir uma placa de metal com uma fina camada de plástico adesivo. Com o buril, revelava-se o desenho na superfície. Uma moeda era colada na parte inferior da placa, permitindo movimentar o suporte com liberdade. A mão que segura o buril quase não se movimenta. É placa que gira a fim de permitir o deslizar do buril. Uma vez que o artista esteja satisfeito com a composição, ele retira o plástico de algumas seções do desenho. A placa toda é mergulhada em ácido. Caso haja a intenção de criar diferentes tonalidades e texturas, uma nova série de seções do desenho tem o plástico retirado e a placa toda é exposta ao ácido novamente. Isso criava gradações de profundidade com que o ácido ataca o metal. Com uma série de rolos de diferentes pesos, Hayter aplicava camadas finas 
de tintas de cores e assim obtinha diferentes intensidades de cor na impressão final.Artistas do Atelier 17 também realizaram a combinação deste método com serigrafia e xilogravura.

Aquele era um espaço para a vivência de artistas dispostos a arriscar. Para Una Johnson, "os críticos e artistas mais conservadores que se opunham ao Surrealismo também refutaram a filosofia e os métodos do Atelier 17. Um número de gravuristas mais tradicionais se sentia ameaçado pelas novas tendências e, sempre que possível, excluíam esse trabalho das exposições nacionais" (JOHNSON, 1 980:77). Hayter teve um papel relevante na formação da vanguarda norte-americana do Pós-Guerra. Motherwell, Rothko e William Baziotes frequentaram seu atelier, mas quem teve uma experiência mais significativa da convivência com Hayter foi Jackson Pollock. O pintor norte-americano conhecia o trabalho do mestre inglês desde os anos 1930 e, por meio de um amigo em comum, John Graham, passou a frequentar o estúdio no outono de 1944.

Ambos os artistas tinham um interesse em automatismo e livre expressionismo abstrato, mas, mais importante, compartilhavam a tendência da expressão dinâmica e linear. (...) A ênfase de Hayter no desenho automático e o estranhamento de trabalhar com uma nova ferramenta parece ter libertado a linha de Pollock da função descritiva e simbólica (MOSER, 1978: 6).

Pollock trabalhou com Hayter no período exatamente anterior ao desenvolvimento de sua fase madura. Enquanto permaneceu no atelier, produziu entre 10 e II pranchas, nenhuma das quais fez tiragens comerciais. Esse fato reforça a tese de que seu mergulho na gravura foi pontual e se devia mais ao interesse em adquirir disciplina e maior liberdade do traço, não por querer se dedicar, necessariamente, à gravura enquanto meio de expressão.

"A ênsafe constante do Atelier 17 na linha reforçou a tendência de Pollock de usá-la como sua fonte primeira de expressão" (MOSER, 1978: 7). A historiadora Joann Moser sugere ainda que a transição de Pollock da pintura de cavalete para a tela estendida no chão se deve à experiência adquirida na gravura, uma vez que o gravurista também trabalha com essa mesma mobilidade de ponto de vista e constantemente altera a orientação de sua prancha. Não era incomum, por exemplo, um gravurista trabalhar na composição de ponta cabeça, girando a placa de metal mediante necessidade, decidindo apenas nos movimentos finais qual deveria ser a orientação da obra. "A inspiração de Pollock ao trabalhar com a tela no chão e se mover entorno de seus quatro lados pode, em parte, ter como origem sua breve experiência como gravurista no Atelier 17 (MOSER, 1978:8).

É grande o legado do Atelier 17 para a arte norte-americana moderna, não só por Pollock e outros nomes da vanguarda que frequentaram o espaço, mas também pela sua influência na sistematização do ensino de gravura no país. Antigos membros do atelier viriam a montar seus próprios estúdios e assumiram posições em departamentos de artes plásticas nas universidades norte-americanas, divulgando os princípios de Hayter para uma nova geração. Gabor Peterdi, por exemplo, inaugurou um estúdio no porão do Brooklyn Museum e assumiu um cargo no Hunter College e na Universidade de Yale. Da mesma forma, Fred Becker foi o fundador de uma oficina na Universidade deWashington em St. Louis em 1948. Segundo o historiador Stephen Coppel, um aspecto importante do impacto de Hayter foi ter feito emergir linhas de pesquisas dentro de instituições acadêmicas com ênfase em procedimentos e avanços técnicos. "Seus ensinamentos no ambiente acadêmico asseguraram a continuação dos preceitos de Hayter como a nova ortodoxia, que veio a dominar a prática da gravura na América durante os anos 1950" (COPPEL, 2008: 33-34). 


\section{Considerações finais}

A doação realizada por Nelson Rockefeller em 1950 trouxe ao Brasil um importante conjunto de gravuras modernas, contemplando uma variedade de métodos e experiências gráficas.A presença de artistas vinculados ao Atelier 17, de Stanley William Hayter, torna essa coleção ilustrativa do debate artístico em curso nos anos 1940, sobre as possibilidades de inovação e abstração de gravura. Além do grupo de gravuristas vinculados a Hayter, a doação que chega ao Brasil também inclui artistas reconhecidos pela serigrafia, como Edward Landon, e por gravuras realistas que retratavam cenas urbanas, como Armin Landeck, reforçando a variedade da coleção.

Até meados dos anos 1940, a gravura assumiu um caráter secundário no campo da arte moderna, sendo a pintura e escultura suportes tradicionalmente mais valorizados pela crítica e pelos colecionadores. Com a criação de departamentos de gravura no MoMA e no Brooklyn Museum e a especialização de curadores, a gravura ganhou outro status no universo artístico norte-americano, auxiliada também pelo surgimento de exposição nacionais e internacionais, bem como clubes de gravura e ateliers dedicados à experimentação do suporte.

Esse artigo evidencia a ligação entre a doação Rockefeller e as propostas curatoriais da exposição Hayter and Studio 17: new directions in gravure (1944) e de Master Prints (1949) do MoMA, bem como das mostras anuais de gravura organizadas pelo Brooklyn Museum. A doação Rockefeller ao antigo MAMSP é, portanto, resultado de um contexto global de apreciação da gravura. A partir desse estudo, é possível melhor compreender a dinâmica de formação dos acervos modernos de São Paulo e melhor situar o núcleo histórico do MAC USP em relação a um movimento de experimentação gráfica, valorização institucional e circulação internacional da gravura moderna produzida nos Estados Unidos em meados do século $X X$.

Fig.4. Tarantelle [Tarantela] (1943). Stanley William Hayter (Reino Unido - 19091988). Verniz mole e buril em cores sobre papel; 55,2 X $33 \mathrm{~cm}$. Coleção MAC USP.

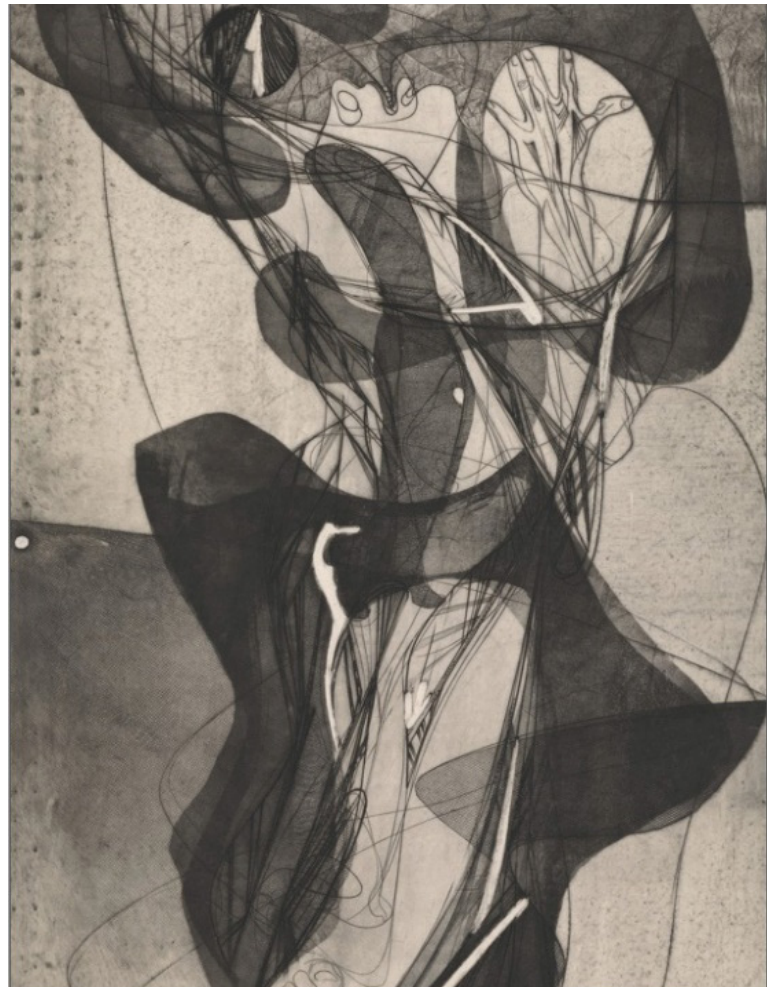


Gravura norte-americana no Museu de Arte Contemporânea da USP: uma análise da doação Nelson Rockefeller de 1950

Fig 5. Sign of the lobster [Sinal da lagosta] ( 1 947-48). Gabor Peterdi (Hungria - 19 I 5 200 I).Verniz mole e água-tinta em cores sobre papel, $50,4 \times 37,7 \mathrm{~cm}$. Coleção MAC USP.

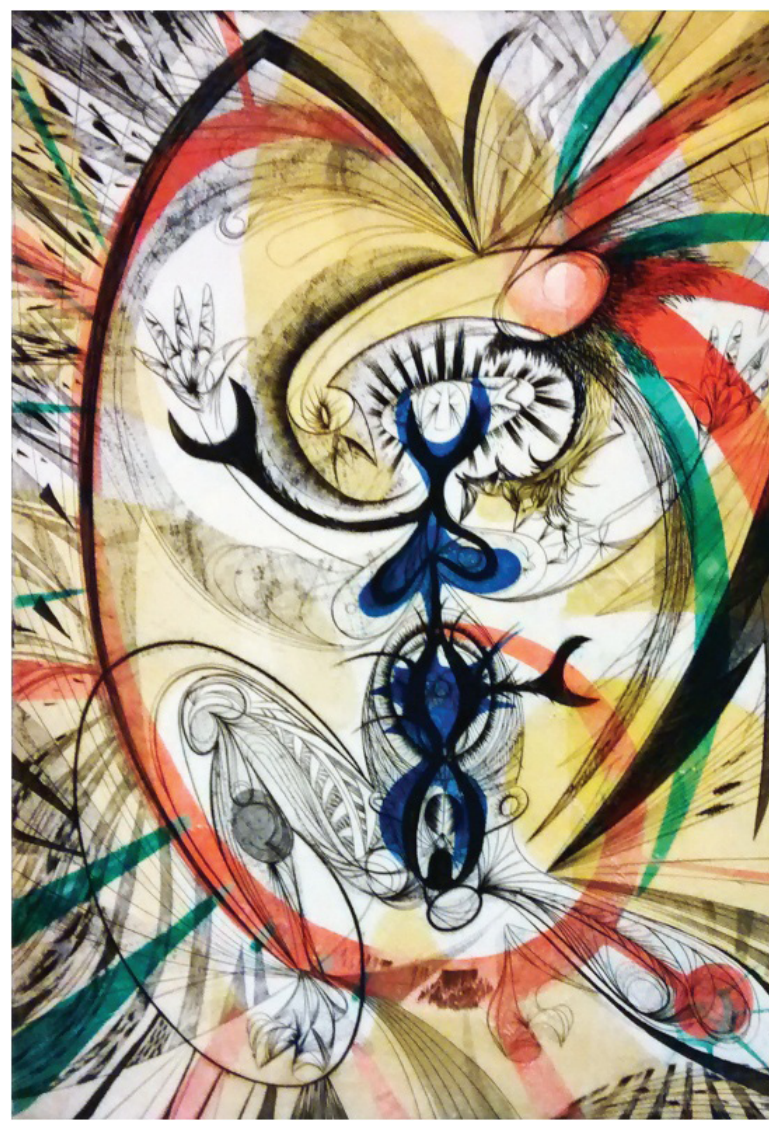

Fig.6.The Sea [O mar] (1949) Boris Margo (Ucrânia - 1902 - I995). Cellocut em cores sobre papel; 42, I X 42,2 cm. Coleção MAC USP.

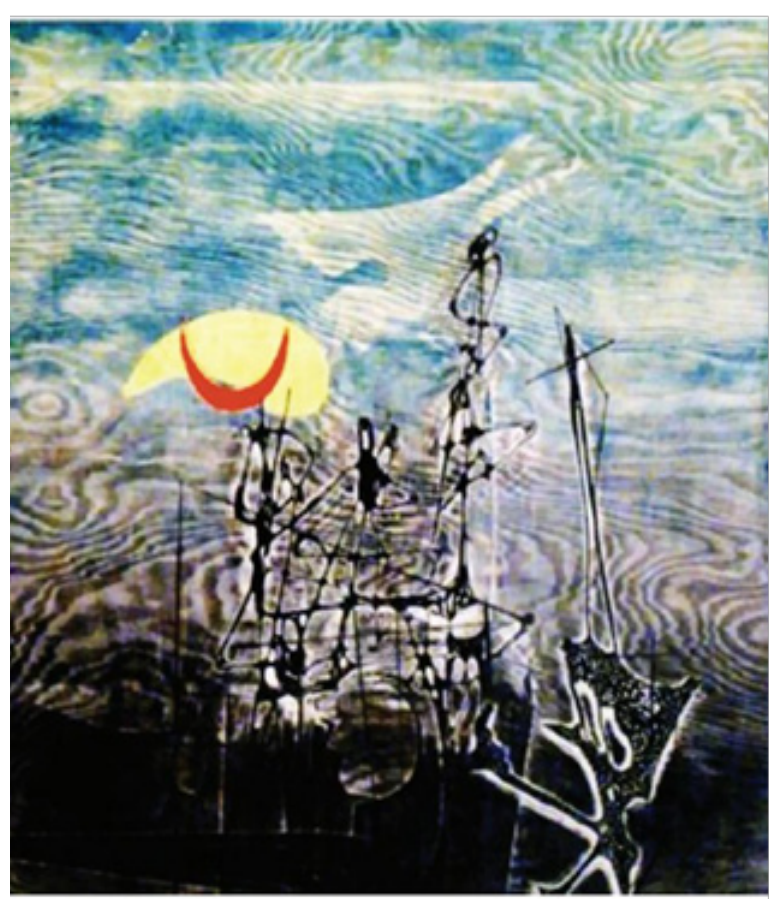


Fig.7. Synthesis [Síntese] (1948). Raymond Jordan (Estados Unidos I 898-?).Verniz mole e buril sobre papel; 45,4 X 35,2 cm. Coleção MAC USP.

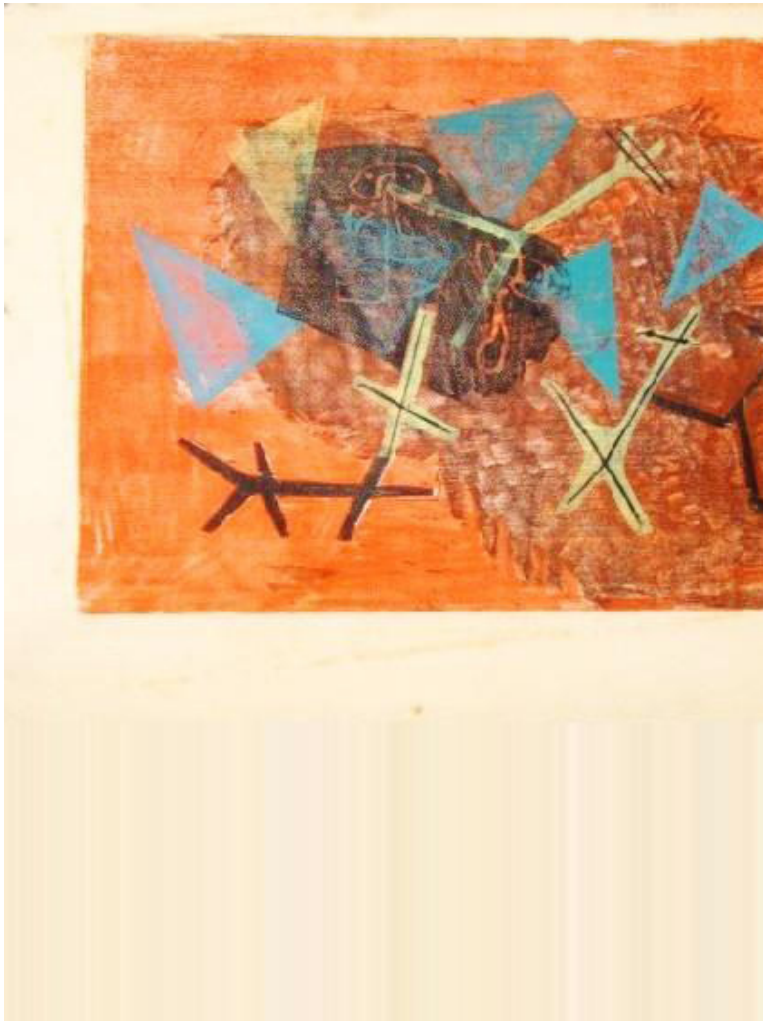

Fig.8. Carnival [Carnaval] (1945). Louis Schanker (Estados Unidos I 903-I 98 I). Xilogravura em cores sobre papel; 36,5 X 53, cm. Coleção MAC USP.

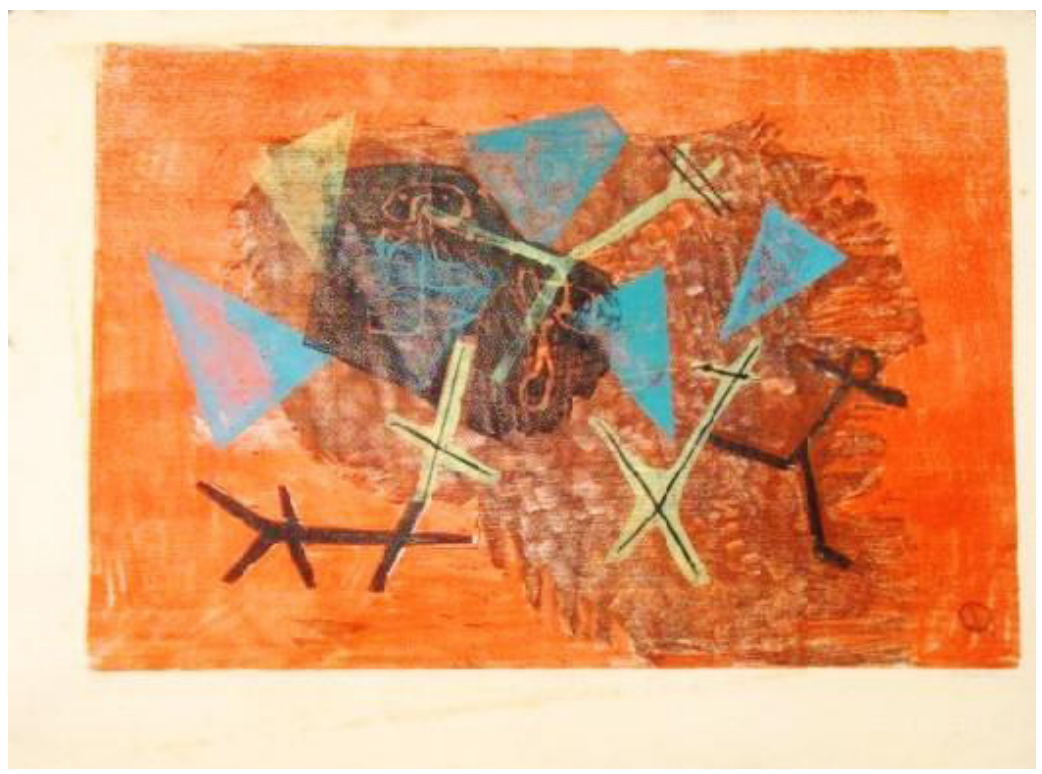


[Fig. 9]. The little act on horseback [Pequeno ato a cavalo] (1949). Seong Moy (China - I92I-20I3). Xilogravura em cores sobre papel; $31,5 \times 32 \mathrm{~cm}$. Coleção MAC USP.

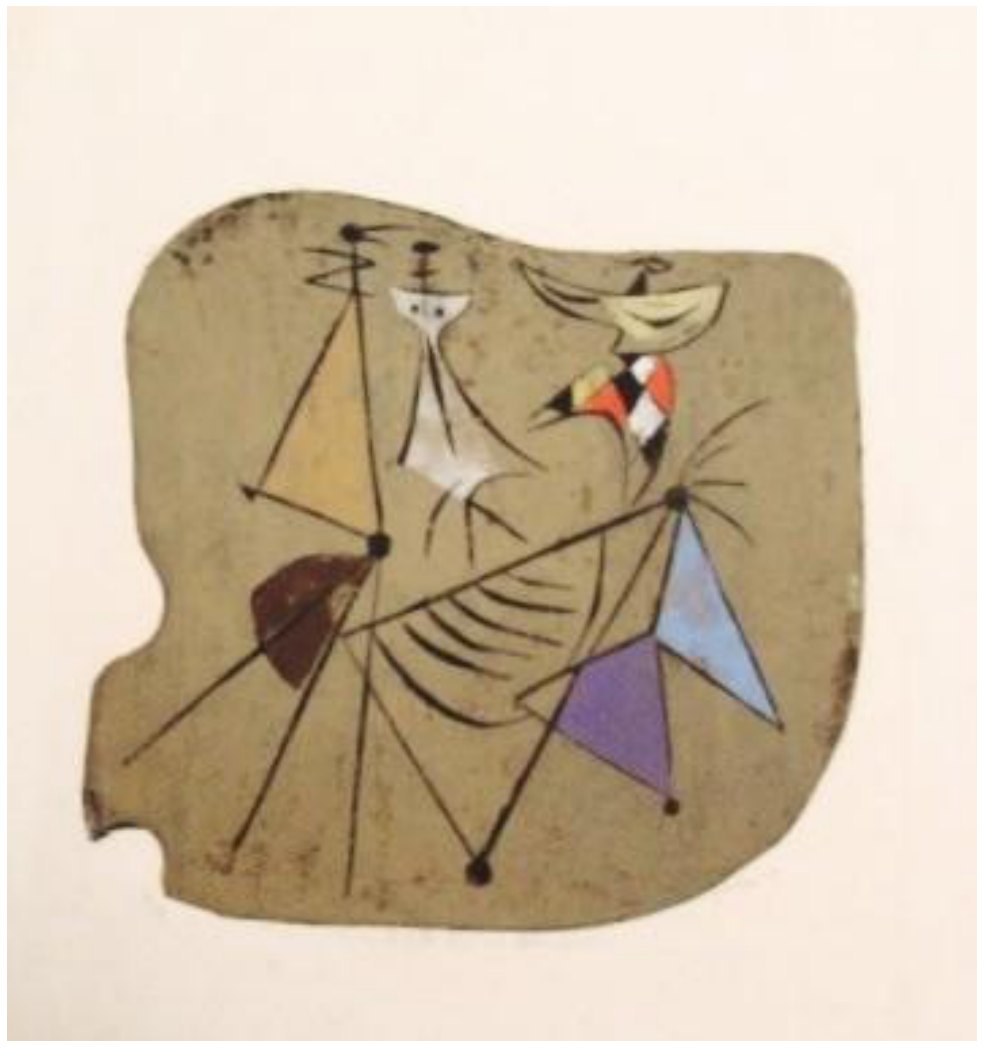

[Fig. 10]. Hen [Galinha] (1945). Sue Fuller (Estados Unidos - I 914 2006). Verniz mole e água-forte sobre papel; $37,4 \times 30,3 \mathrm{~cm}$. Coleção MAC USP.

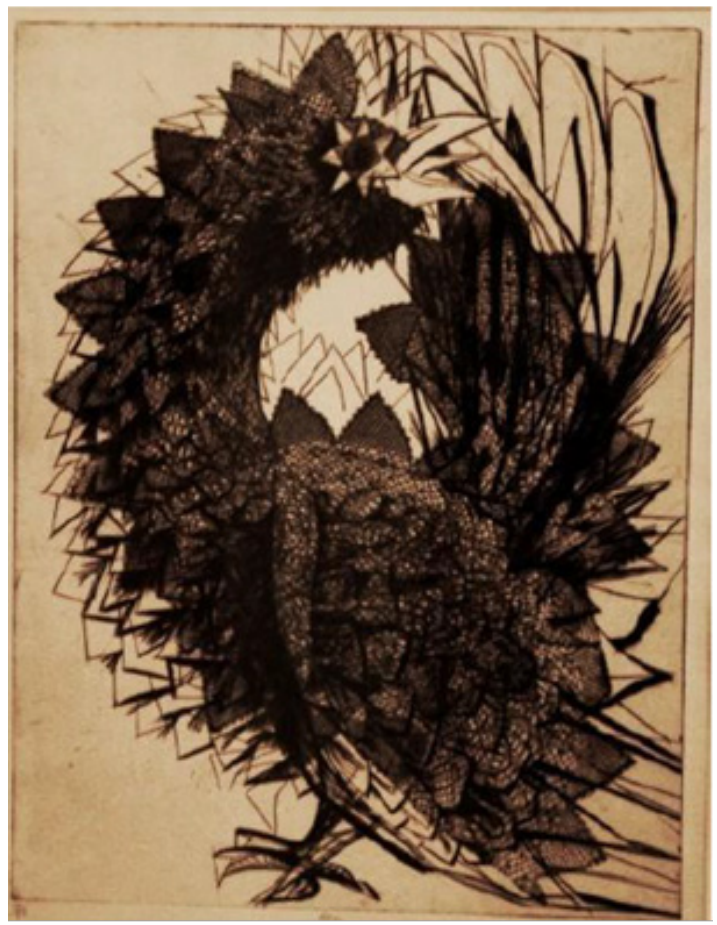




\section{Referências}

AMARAL, Aracy. A História de uma Coleção em Museu de Arte Contemporânea de São Paulo: perfil de um acervo. São Paulo:Techint, 1988.

BARR, Alfred. Modern Prints and the Museum em The Abby Rockefeller Print Room, Master Prints from the Collection, Museum of Modern Art Bulletin 16, no.4, 1949.

CATÁLOGO da exposição Gravadores norte-americanos, Museu de Arte Moderna de São Paulo, 10 de abril a 06 de maio de 195I. Rockefeller Archive Center. Coleção Nelson A. Rockefeller.

CATÁLOGO da exposição American Printmakers, Galeria Buchholz, 1945. Archives of American Art, Smithsonian Institution, Washington D.C. CIRCULATING EXHIBITIONS 193I-1954. The Bulletin of the Museum of Modern Art.Vol. 2 I, No. 3/4,Verão, 1954, pp. 3-30.

COMUNICADO à imprensa, Master Prints, an exhibition of 230 American and European prints, to commemorate opening of Abby Aldrich Rockefeller Print room at museum. 06 mai. 1949. Disponível: http://www.moma.org/pdfs/docs/

press_archives//324/releases/MOMA_1949 $0038 \quad$ 1949-05-06_490506-36. pdf?20l0 - Acessado em 24.0I.20I4.

COPPEL, Stephen. American prints: from Hopper to Pollock. Burlington: Lund Humphries, 2008. 272p.

DOSS, Erica. Catering to consumerism: Associated American Artists and the Marketing of Modern Art, 1934- 1958. In Winterthur Portfolio, 199I, Inc. Vol 26, p. 145

EHXIBITION HISTORY list MoMA (1940-1949).Arquivo do MoMA. Disponível em: https://www.moma.org/research-and-learning/research-resources/archives/ archives_exhibition_history_list

GUILBAUT, Serge. How New York stole the idea of modern art abstract expressionism, freedom, and the cold war. Chicago; London; The University of Chicago, 1983.

HAYTER, S.W. New Ways of Gravure. Londres: Oxford University Press, 1966. About Prints, 1962. London: Oxford University Press,

1962. 176p.

HARRIS, Jonathan. Federal Art and National Culture - The Politics of Identity in New Deal America. New York: Cambridge University Press, 1995.

JOHNSON, Una. American prints and printmakers: a chronicle of over 400 artists and their prints from 1900 to the present. Nova York: Doubleday \& Company, Inc,. Garden City, 1980. 266p.

Ten years of American prints, 1947-1956. New

York: Brooklyn Museum, 1956. Disponível: http://hdl.handle.net/2027/ ucl.32106001489I26 - Acessado em 20.01.2014.

LÉVY, Sophie e DEROUET, Christian (ed).A Transatlantic Avant-Garde:American Artists in Paris, 1918-1939. Terra Foundation for the Arts, 2003.

LIEBERMAN, William. The Print Collection em The Bulletin of the Museum of Modern Art. Vol. 16, No. 4, The Abby Aldrich Rockefeller Print Room: Master Prints from the Museum Collection (1949), pp. 9-13. Disponível: http://www. jstor.org/stable/4058197

Entrevista com o curador realizada pelo Oral MoMA 
em 18 de dezembro de 1990, MoMA Archives.

LOEBL, Suzanne. America's Medicis: The Rockefellers and Their Astonishing Cultural Legacy, Harper, 2010. LYTLE, [Dorohy L.] (carta) 28 de junho de 1950, Nova York [para] BOYER, Nova York. 2f. Documento pertencente ao Rockefeller Archive Center. Coleção Nelson A. Rockefeller. Grupo: Museus, Série III 4L, Caixa I48, Pasta I470.

MOSER, Joann.The Impact of StanleyWilliam Hayter on Post-War American Art: Archives of American Art Journal,Washington, v. I8, n. I, pp. 2-I I. 1978. Disponível em http://www.jstor.org/stable/I5572II - Acesso em: 04 ago. 2013.

MOY, Seong. Oral history interview with Seong Moy, I 971 Jan. 18-28,Archives of American Art, Smithsonian Institution.

SCHRAG, Karl. Oral history interview with Karl Schrag. 1970 Out. 14-20,Archives of American Art, Smithsonian Institution.

SWEENEY, James Johnson. The Bulletin of the Museum of Modern Art. Vol. 12, No. I,Aug., 1944.

TOLEDO, Carolina.As doações Nelson Rockefeller no acervo do Museu de Arte Contemporânea da USP. Dissertação (Mestrado) - Programa Interunidades em Estética e História da Arte da Universidade de São Paulo. São Paulo, 2015. 